\title{
A Systematic Literature Review on Software Reliability Estimation Model for Measuring the Effectiveness of Object Oriented Design
}

\author{
Surabhi Saxena ${ }^{1}$, Dr. Devendra Agarwal ${ }^{2}$ \\ Ph.D. Research Scholar, Department of Computer Application, Babu Banarasi Das University (BBDU), Lucknow \\ (U.P.) India ${ }^{1}$ \\ Director Babu Banarasi Das Northern India Institute of Technology (BBDNIIT), Lucknow (U.P.) India ${ }^{2}$

\begin{abstract}
Software Reliability is one of the most important quality indicator for software development life cycle process. It is perfectly measured and support to increase the development process. Somewhere the software quality depends upon the reliable measurement. A number of software reliability theories have been published in different types of journals by researcher and practitioners. On the other hand reliability is a always big questions in complex system. This research paper shows the outcomes of a systematic literature review conducted on software reliability of object oriented design.
\end{abstract}

Keywords: Software Reliability, Software Reliability estimation model, Object Oriented design, Industrial Perspective.

\section{INTRODUCTION}

Software reliability is an important factor to estimate software quality. Software reliability is a probably that software will not cause the failure of a system for a specified time under specified condition. According to the ISO/IEC 25010:2011 product quality model defines reliability as the degree to which a system, component or product performs specified functions under specified conditions for a specified period of time.

Software Reliability is a one of the key factor among the eight functional characteristics of quality model that contributes to the efficiency of the software system which was further divided into sub-characteristics which are maturity, availability, fault tolerance and availability. Just like hardware, the reliability of software can be measured and evaluated [2].

\section{SOFTWARE RELIABILITY}

According to the IEEE-Std 729-1991 "Software Reliability is defined as the probability of failure - free operations for a specified period of time in a specified background."

According to the ISO9126:"Reliability is the capacity of the software product to continue a particular level of performance when used under specific situation."

Following figure 1. (a) shows the relation between error, faults and failures. In terms of software reliability, error is a computer programmer action or hops that result in a fault.

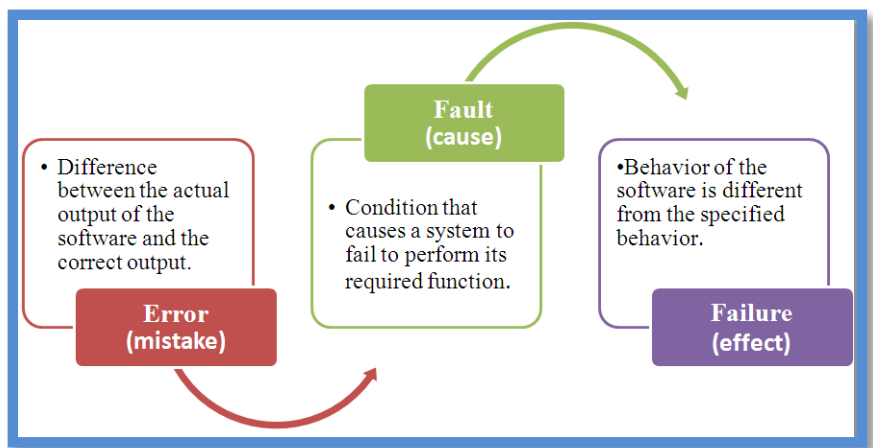

Fig.1 Life Cycle of Software Failure 
A fault is a software defect that causes failure. A failure is the inability of a system or component to perform a required function according to its specification. Reliability Metrics are used to know the possibility of failure or failure rate of software where system error are occurs.

Software failures occur if the behavior of the software differs from the specified behavior of the software. A failure in the software design makes the system difficult to understand and increases the complexity [1].

\section{OBJECT ORIENTED METRICS}

The object-oriented technology is more trustworthy to design the software in order to make available the product of higher quality. The recognition of the object-oriented approach is credible to produce improved and cheaper software [4]. Three important concepts formulate a distinction the object-oriented approach from conventional software engineering: Coupling, Encapsulation, Cohesion and Inheritance \& Polymorphism [4].

The object oriented design metrics used for evaluating object oriented design and selecting an optimal design among alternatives with respect to reliability. Object Oriented design and metrics give out results for the measurement for a system element for a software measurement then these Object Oriented reliability metrics are used for finding out the ranking of software reliability .

The following software reliability metric are identified during the whole research work :-

$>$ Inherited Complexity Metric

$>$ Cohension Complexity Metric

$>$ Encapsulation Complexity Metric

$>$ Coupling Metric

\section{SOFTWARE RELIABILITY MODELS}

According to the Software Engineering Concepts, Software Reliability is divided in two types of software named as the prediction models and estimation models.

Table 1:- Comparison Between Prediction and Estimation Model

\begin{tabular}{|l|l||l||}
\hline \multicolumn{1}{|c|}{ Issues } & \multicolumn{1}{|c|}{ Predication Model } & \multicolumn{1}{|c|}{ Estimation Model } \\
\hline \hline Data Reference & $\begin{array}{l}\text { In this Model Historical Data } \\
\text { are used in predication model }\end{array}$ & $\begin{array}{l}\text { The Data from current software } \\
\text { development is used in estimation model. }\end{array}$ \\
\hline \hline $\begin{array}{l}\text { At the time of use in } \\
\text { the development cycle }\end{array}$ & $\begin{array}{l}\text { Generally it is used in testing } \\
\text { phase. }\end{array}$ & $\begin{array}{l}\text { This type of reliability model is used in } \\
\text { development Phase and Design phase. }\end{array}$ \\
\hline \hline Time Frame & $\begin{array}{l}\text { The reliability can be predicated } \\
\text { at the same future time }\end{array}$ & $\begin{array}{l}\text { The reliability can be estimate at either } \\
\text { future or present time }\end{array}$ \\
\hline
\end{tabular}

\section{RESEARCH OBJECTIVE}

The main objective is to develop a consolidated framework to software reliability model at the development phase of the software development life cycle The Primary objective of this research is to remove all the faults which was critical to both software and hardware growth. The secondary research objective is to remove all the faults which was encountered often by the users

\section{REVIEW METHODOLOGY}

A systematic literature review for recognize, estimate and to understand the existing research to a particular area of research. The research study is categorized into 2 way i.e. primary and secondary data source. Primary study is done by individually and secondary research done systematic review of other research paper which is related to research area and topic. The important research papers review in detail is to determine its effectiveness with respect to the literature review. Out of 85 papers 50 papers were extracted from the journals, transactions and conference etc to optimize the objectives of the research.

In this paper study the systematic review is used to find out the reliability factors and measurement taken in software engineering which help to proposed new software reliability estimation model for reliable system. 
Several models have been developed and proposed since 1970 however some are similar in work principle and some are different. One of the earliest model was the Rome Laboratory TR-92-52. It was developed in 1987 and then updated in year 1992 and was generated for avionics systems .Some of other models are Shortcut model, Full-scale model, and Neufelder assessment model. Some of the software prediction models include Musa's Execution Time Model, Putnam's Model. and Rome Laboratory models TR-92-51 and TR-92-52, etc.

Using software reliability prediction models, software reliability can be predicted early in the development phase and enhancements can be initiated to improve the reliability. Some of the software reliability estimation models include exponential distribution models, Weibull distribution model, Thompson and Chelson's model, etc. Exponential models and Weibull distribution model are usually named as classical fault count/fault rate estimation models, while Thompson and Chelson's model belong to Bayesian fault rate estimation models.

A complete comparative study of existing Software reliability Models Consider by Various researchers and Expert has been done in Table2.

Table 2 A Systematic Literature Reviews of Software Reliability Models Proposed by Various Researchers

\begin{tabular}{|c|c|c|c|}
\hline Year & Author (s) & Methodology & Model \\
\hline 2002 & "M.M.T Thwin \& T.S. Quah & $\begin{array}{l}\text { Object Oriented metrics for } \\
\text { reliability and maintainability }\end{array}$ & $\begin{array}{l}\text { Multiple Regression Model and } \\
\text { Neural Network Model }\end{array}$ \\
\hline 2007 & N.R.Kiran \& V.Ravi & $\begin{array}{l}\text { Software Reliability predication } \\
\text { model }\end{array}$ & $\begin{array}{c}\text { BPNN , DEFNIS , MARS \& } \\
\text { MLR }\end{array}$ \\
\hline 2009 & K.Khataneh \& T.Mustafa & $\begin{array}{c}\text { Exploration Software Reliability } \\
\text { Model }\end{array}$ & Fuzzy Logic Model \\
\hline 2010 & N.F.Scheid Wind & $\begin{array}{l}\text { Use of UML Diagram for design } \\
\text { process }\end{array}$ & "Object Oriented Design \\
\hline 2011 & S.A.Hudli \& A.V.Hudli & \begin{tabular}{|c|} 
Estimate the addressing of \\
reliability of object Oriented Design
\end{tabular} & Reliability Metrics \\
\hline 2012 & Y.Wu \& R.Yang & Reliability Predication Model & $\begin{array}{c}\text { General Regression Neural } \\
\text { Network }\end{array}$ \\
\hline 2012 & B. Kotaiah and R.A. Khan & $\begin{array}{c}\text { Survey on software reliability } \\
\text { assessment }\end{array}$ & $\begin{array}{c}\text { ANN, fuzzy } \\
\text { network, genetic algorithm, } \\
\text { SVM, Bayesian classification }\end{array}$ \\
\hline 2013 & G. Agarwal \& V.K. Gupta & Reliability of Software Modules & Neural network approach \\
\hline 2013 & M.Arora \& S. Chaudhary & $\begin{array}{c}\text { Predication Software Reliability } \\
\text { Model }\end{array}$ & Neural network approach \\
\hline 2013 & A. Pandey \& A.Ahlawat & $\begin{array}{c}\text { To predict the } \\
\text { software reliability and } \\
\text { maintainability using object } \\
\text { oriented metrics }\end{array}$ & $\begin{array}{c}\text { Back Propagation Neural } \\
\text { Network approach }\end{array}$ \\
\hline 2014 & N. Sharma \& P. Bano & "Reliability Estimation Model & "Survey Questionnaire \\
\hline 2015 & N. Gupta \& R. Kumar & $\begin{array}{l}\text { Measurement of } \\
\text { reliability in object } \\
\text { oriented design }\end{array}$ & Systematic review \\
\hline 2016 & A. Mishra \& S.K. Dubey & $\begin{array}{l}\text { reliability of object } \\
\text { oriented software using } \\
\text { fuzzy approach }\end{array}$ & $\begin{array}{c}\text { ISO/IEC } 9126 \text { model and CK } \\
\text { Metrics }\end{array}$ \\
\hline
\end{tabular}


Vol. 6, Issue 6, June 2017

\section{CONCLUSION AND FUTURE WORK}

Most of the software reliability techniques are reviewed and still diff difficult to apply in applications. A lot of Reliability work has been proposed in the existing literature review for evaluating software reliability . A review of literature shows that the most work have been done at the phase of software development life cycle especially at coding and testing level. For that reason the evolution of software reliability to make reliable system still unsolved and the customer of system are unstill unsatisfied. Software complexity is one of the drawbacks from the growth of the reliable systems. In future research paper the new consolidated framework for Software Reliability Estimation Model has been proposed so that the quality and complexity well maintained

\section{REFERENCES}

[1] S. Khatri R.S., Chillar and A. Chhikara. 2012. "Analyzing the Impact of the Software Reliability Growth Models on Object Oriented Systems during the Testing" ,International Journal of Enterprise Computing and Business Systems. Volume No2 Issue No. 1.

[2] K.K. Agarwal, Yogesh Singh.”Software engineering. " New Age International Publishers, Jan 1, 2005

[3] A.L. Goel. 1985. Software Reliability Models: Assumptions, Limitations, and Applicability. IEEE Trans. Software Engineering.

[4] J.D. Musa, A. Ianino and K. Okumoto. 1987. Software Reliability Measurement, Prediction, Applications. McGraw-Hill, Inc.

[5] A. L. Goel, and K. Okumoto. 1979. Time-Dependent error-Detection Rate Model for Software Reliability and Other Performance Measures. IEEE transactions on Reliability. Vol. R-28, No. 3, pp. 206-11

[6] M. Jedlicka, O. Moravcik and P. Schreiber. 2008.Survey to Software Reliability. Central European Conference on Infor mation and Intelligent Systems, CECIIS.

[7]Y.K. Malaiya and P.K. Srimani. 1990. Software Reliability Models: Theoretical Developments, Evaluation and Applications. IEEE Computer Society Press.

[8] M.H. Tang, M.H. Kao and M.H. Chen. 1999. An empirical study on object-oriented metrics. Proceedings of the Sixth IEEE International Symposium on Software Metrics.

[9]G. Aggarwal and V.K. Gupta. 2013. Neural Network Approach to Measure Reliability of Software Modules: A Review. International Journal of Advances in Engineering Sciences. 3(2).

[10]S.A. Hudli and A.V. Hudli. 2011. Impact of complexity of object-oriented design on software reliability," In proceeding of International Conference on Quality and Reliability Engineering ICQRE.

[11] N. Sharma and P. Bano. 2013. A Survey of Software Reliability Factor. IOSR Journal of Computer Engineering. 12(1).

[12] N. Gupta and R. Kumar. 2014. Reliability Measurement of an Object Oriented Design: A Systematic Review. International Journal of Scientific Engineering and Technology. 3(12).

[13] N.R. Kiran and V. Ravi. 2007. Software reliability prediction by soft computing techniques. The Journal of Systems and Software.

[14] D. Kumar and A.G. Dinker. 2014. Enhancement of Reliability in Object-Oriented Software Reliability Model. International Journal of Advanced Research in Computer Science and Software Engineering.

[15] B. Kotaiah and R.A. Khan. 2012. A Survey on Software Reliability Assessment by Using Different Machine Learning Techniques. International Journal of Scientific and Engineering Research (IJSER).

[16] McCall, J.A., Richards, P.K., and Walters, G.F., (1977) "Factors in Software Quality", RADC TR-77-369, Vols I, II, III, US Rome Air Development Center Reports.

[17] Aasia Quyoum, Mehraj-Ud - Din Dar, S. M. K. Quadri "Improving Software Reliability using Software Engineering Approach- A Review" in International Journal of Computer Applications (0975-8885) Volume 10, November 2010.

[18] Royce "Managing the Development of Large Software Systems: Concepts and Techniques" in Proc. WESCON, IEEE Computer society

[19] Ian Sommerville "Software Engineering" Eight Edition, Pearson Education, 2009.

[20] Barry Boehm (1996). "A Spiral Model of Software Development and Enhancement". In: ACM SIGSOFT Software Engineering Notes (ACM) 11(4):14-24, August 1986.

[21] Richard H. Thayer, Barry W. Boehm Tutorial: software engineering project management. Computer Society Press of the IEEE, 1986.

[22] Kuhn, D.L (1989). "Selecting and effectively using a computer aided software engineering tool". Annual Westinghouse computer symposium; Pittsburgh, PA (USA); DOE Project 6-7 Nov, 1989.

[23] Pankaj Nagar and Blessy Thankachan: "Software Reliability:- A Review ", International Journal of Applied Physics and Mathematics, Vol. 1, No. 2, September 2011

[24] Durga Patel, Pallavi ", Software Reliability: Models", International Journal of Computer Applications (0975 - 8887) Volume 152 - No.9, October 2016.

[25] A.Yadav \& R. A. Khan, Nov 2009 “Critical Review on Software Reliability Models”, Int. J. Recent Trends in Engineering and Technology, Vol -2 , No. 3, pp-114-116.

[26] Gaurav Aggarwal,Dr.V. K Gupta,January 2014 "Software Reliability Growth Model”, International Journal of Advanced Research in Computer Science and software engineering, Vol.4, Issue.1,pp- 475-479.

[27] Razeef Mohd,Mohsin Nazir,September 2012,"Software Reliability Growth Models: Overview and Applications", Journal of Emerging Trends in Computing and Information Sciences, Vol.3, No.9, pp-1309-1320.

[29]Mohd. Anjum, Md. Asraful Haque, Nesar Ahmad,January 2013 "Analysis and Ranking of Software Reliability Models Based on Weighted Criteria Value",I.J.Information Technology and Computer Science,

[30]Weyuker, E., Evaluating software complexity measures. IEEE Transactions on Software Engineering, v.14: p. 1357-1365, 1988.

[31] Chahat Sharma And Sanjay Kumar Dubey, " A Perspective Approach Of Software Reliability Models And Techniques", ARPN Journal Of Engineering And Applied Sciences, Vol. 10, No. 16, September 2015

[32] Manjula.C.M.Prasad, Dr. Lilly Flowrence, Dr. C.V. Srikrishna," Overview of Software Reliability Models", International Journal of Engineering and Management Research Volume-3, Issue-5, October-2013

[33] Aasia Quyoum, Mehraj - Ud - Din Dar, S. M. K. Quadri, "Improving Software Reliability using Software Engineering Approach- A Review",International Journal of Computer Applications (0975 - 8887)Volume 10- No.5, November 2010.

[34] Sawada, K., Sandoh, H., "A Summary of Software Reliability Testing Models", International Journal of Reliability, Quality and Safety Engineering, 1999.

[35]Schneidewind,N.F., "Software Reliability Measurement", Reliability Review, The R\&M Engineering Journal, 2003. 